\title{
The Association between Shift Work and the Metabolic Syndrome in Female Workers
}

\author{
Han Hui Ye, Jae Uk Jeong, Man Joong Jeon ${ }^{*}$ and Joon Sakong
}

\begin{abstract}
Objective: This study aimed to determine identify any association between shift work and the metabolic syndrome by comparing the prevalence rates of the metabolic syndrome in shift work groups and daytime work groups for female workers.

Methods: Based on data from health examinations carried out from April to December of 2012, we selected as our subjects 254 female workers from the Daegu area Dyeing Industrial Complex. We diagnosed the metabolic syndrome using the examination results, and information about age, whether or not they did shift work, job type, smoking habits, drinking habits, exercise habits, and past medical history was collected through self-administered questionnaire surveys and face-to-face interviews. The variables found in a univariate analysis to be significant in the occurrence of the metabolic syndrome - age, drinking habits, exercise habits, and shift work - were included in a logistic regression analysis of the risk of the metabolic syndrome for female workers.
\end{abstract}

Results: The prevalence rates of the metabolic syndrome for the total group of study subjects was $11.8 \%$, for daytime workers was 2.8\%, and for shift workers was 15.3\%. A logistic regression analysis of the odds of the metabolic syndrome for female workers was conducted that included factors associated with the occurrence of the metabolic syndrome: age, drinking habits, exercise habits, and shift work. The results revealed that the odds ratio of the metabolic syndrome in the shift work group, 6.30 (95\% Cl 1.24-32.15), was significantly higher when compared with the daytime work group.

Conclusion: Shift work appears to have an association with the metabolic syndrome in female workers. Accordingly, we believe that the attention of government agencies and business owners is needed together with the individual practice of health behaviors to manage the metabolic syndrome for the prevention of cardiovascular disease in female shift workers.

Keywords: Shift work, Female workers, Metabolic syndrome

\section{Introduction}

The metabolic syndrome, a state of insulin resistance, is a syndrome that is accompanied by abdominal obesity, lipoidosis, impaired glucose tolerance, and high blood pressure [1]. After being named "syndrome X" by Reaven [2] the cluster of cardiovascular disease risk factors was named the metabolic syndrome and diagnosis criteria was first proposed by the World Health Organization (WHO) [3]. Later, in 2001, the United States National Cholesterol Education Program Adult Treatment Panel (NCEP-ATP) III emphasized the importance of the

\footnotetext{
* Correspondence: mjoong@yu.ac.kr

Department of Occupational and Environmental Medicine, Yeungnam

University Hospital, 317-1, Daemyungdong, Namgu, Daegu 705-717, Republic of Korea
}

\section{Biomed Central}

metabolic syndrome for managing cardiovascular problems and proposed standards for diagnosing the metabolic syndrome that required three or more of the following criteria to be met: abdominal obesity, hypertriglyceridemia, low high-density lipoprotein cholesterolemia, high-blood pressure, and impaired glucose tolerance [4]. In 2005, the International Diabetes Federation (IDF) proposed new diagnosis criteria that modified the NCEP-ATP III, noting the high relation to insulin resistance, and proposed abdominal obesity, an easy clinical measurement, as a diagnostic prerequisite [5]. In addition, in 2005, the American Heart Association/ National Heart Lung and Blood Institute (AHA/NGLBI) modified the diagnostic criterion for impaired fasting 
glucose and the use of medication as a risk factor, based on NCEP-ATP III [6].

The metabolic syndrome increases the risk of diabetes and cardiovascular disease, as well as the death rate from these diseases [7]. In the United States, 34\% of adults over 20 have the metabolic syndrome, and the rate continues to increase [8]. The results of an analysis of data gathered from the Korean National Health and Nutrition Examination Surveys (KNHANES) from 2007-2010 showed the prevalence rate of the metabolic syndrome in South Korea for adults over 30 to be $31.9 \%$ for men and $25.6 \%$ for women, with a total prevalence of $28.8 \%$ [9]. This is important, not only from a clinical perspective, but from a public health perspective as well [10].

While shift work is being adopted by companies for economic, technical, and social reasons, it means dividing workers into two or more groups so that they work in shifts at separate times. This definition excludes temporary or occasional night work, night duty done by daytime workers, and fixed-time work cycles in which workers do not change shifts. The method of shift work can be divided into shifts that include night work and shifts that do not, as well as 24-hour periods divided into two 12-hour or three 8-hour shifts that rotate every 4-5 days [11]. 20-25\% of manufacturing workers in Europe and the United States perform shift work [12]. In South Korea, the results of a study by the Ministry of Employment and Labor in 2011 on companies with 10 or more employees $(3,414$ samples) revealed the proportion of shift workers to be $15.2 \%$ [13].

Human physiology has a circadian rhythm of about 24 hours, which is maintained by the interaction of environmental conditions and the biological clock [14]. The disruption of the circadian rhythm that results from shift work has been reported to lead not only to problems such as sleep disorders and exhaustion, but also to domestic life and social activity problems [15], as well as various health problems [16].

Shift work-related health problems include an increase in digestive system problems, drowsiness, exhaustion, and sleep disorders [17]. They also include a metabolic syndrome-related increase in body fat, as well as a rise in blood pressure, which, through an increase in ischemic heart disease and cardiovascular problems, has led to an increase in mortality rates [18]. In women, there are also reports of an association with breast cancer, menstrual irregularity, and infertility [19].

Research on the factors that influence the development and prevalence of the metabolic syndrome in Korean workers, as well as on the physical harm caused by shift work, has mainly focused on male workers in dockyards, electronics manufacturing, and steel-mills $[20,21]$. While there has been one study on female workers that examined the association of shift work duration and cardiovascular disease risk factors in university hospital nurses [22], there is still an insufficient number of studies on the association of shift work and the metabolic syndrome in female manufacturing workers.

Accordingly, this study was carried out to provide baseline data about the health management and prevention of metabolic syndrome-linked disease in female shift workers and to investigate the association between shift work and the metabolic syndrome in female workers in dye-related jobs.

\section{Materials and methods}

1. Research objectives

Out of the 343 female workers from the 19 fabric processing businesses located in the Dyeing Industrial Complex near the city of Daegu, 257 participated in the medical examination (74.9\% participation rate) in the Department of Occupational and Environmental Medicine at ' $\mathrm{Y}$ ' University Hospital from April until December of 2012. Among those, excluding 3 individuals with a medical history of thyroid disease, 254 individuals were included as subjects in this study. This study was conducted in compliance with the international "Declaration of Helsinki". The Institutional Review Board of our university hospital approved the study protocol.

\section{Research methods \\ 1) Data collection}

In the process of conducting regular and special medical examinations on workers, we inquired about their past medical history, habits of exercise, smoking, drinking, type of work, and whether or not they did shift work through interview-based medical examinations. Height and weight were measured using automated height and weight measuring devices with the subjects lightly clothed and their shoes removed. For the waist circumference, we measured midway between the pelvic iliac crest and the lower hypochondrium in an upright posture, in accordance with the WHO's diagnostic criteria for abdominal obesity [23]. Blood pressure was measured with a mercury blood pressure monitor after the subject had rested for at least 4 minutes while sitting. Blood samples were collected from the study subjects between 8-10 a.m. after fasting for a minimum of 8 hours under the guidance of the company health administrator, and blood glucose, triglycerides, and high-density lipoprotein cholesterol were measured using an automated chemistry analyzer (Olympus AU5400). Shift workers were not 
examined on a day in which they worked a late night/ early morning shift. Instead, they were examined on a day when they worked a morning or day shift.

\section{2) Diagnostic criteria for the metabolic syndrome}

For the diagnostic criteria for the metabolic syndrome, we used the modified ATP III definition proposed by the American Heart Association/National Heart, Lung and Blood Institute (AHA/NGLBI) in 2005 [5] based on the standards set in the 2001 NCEP-ATP III [4]. For the abdominal obesity criterion, we used Korean-specific waist circumference values $(90 \mathrm{~cm}$ for men, $85 \mathrm{~cm}$ for women) proposed in 2005 by the Korean Society for the Study of Obesity [24]. Thus, the metabolic syndrome can be diagnosed by meeting 3 or more of the 5 criteria: a waist circumference of $85 \mathrm{~cm}$ and above; triglyceride levels of $150 \mathrm{mg} / \mathrm{dL}$ or greater, or taking medication to lower triglyceride levels; a high-density lipoprotein (HDL) cholesterol level under $50 \mathrm{mg} / \mathrm{dL}$, or taking medication to raise HDL levels; systolic blood pressure at or above $130 \mathrm{mmHg}$, or diastolic blood pressure at or above $85 \mathrm{mmHg}$, or taking antihypertensive medication; fasting blood glucose of $100 \mathrm{mg} / \mathrm{dL}$ or higher, or taking medication to blood glucose.

\section{3) Daytime workers and shift workers}

Daytime workers were defined as those individuals who worked from 7-8 am to 5-6 pm, while the rest those who worked 2 shifts of 8 hours, 2 shifts of 12 hours, or 3 shifts of 8 hours - were considered shift workers.

\section{Data analysis}

The collected data was analyzed using the statistical program SPSS version 18.0 (SPSS, Inc., Chicago, IL, USA). The research subjects were divided into a daytime work group and a shift work group, after which the general characteristics, physical measurements, and examination findings, as well the frequency of abnormalities for each metabolic syndrome component, were analyzed for both groups, using the chi-squared test, Fisher's exact test, and t test. In addition, in order to analyze the factors that influence the prevalence of the metabolic syndrome in female workers, we conducted a logistic regression analysis using the prevalence of the metabolic syndrome as a dependent variable, selecting only those factors that yielded a p-value of 0.25 or lower in a univariate analysis, and calculated the odds ratio and its 95\% confidence interval. The level of statistical significance was set at a p-value of less than 0.05 .

\section{Results}

1. General characteristics of the research subjects

Among the research subjects, there were 71 individuals in the day work group (28.0\%) and 183 in the shift work group (72.0\%). The average age for the day work group was $36.4 \pm 12.5$ years $(18-76)$. The shift work group, with an average age of $49.7 \pm 8.6$ years (21-70), was significantly older $(\mathrm{p}<0.001)$. A majority of the day work group, 46 individuals (64.8\%), were under 40 years old, whereas a majority of the shift work group, 102 individuals (55.7\%), were $40-49$ years old.

Subjects that currently smoked included 1 from the daytime group (1.4\%) and 2 from the shiftwork group (1.1\%). Among the individuals who consumed alcohol at least once a week, 36 (50.7\%) were daytime workers. This was a higher rate of alcohol consumption $(\mathrm{p}=0.040)$ compared to the 67 shift workers (36.6\%) who drank at least once a week. Among the individuals who exercised regularly at least once a week, the daytime work group exercised at a higher rate $(\mathrm{p}=0.011)$, with 61 individuals (85.9\%), compared to the shift work group with 129 individuals (70.5\%).

Concerning past disease history, 3 individuals from the daytime work group (4.2\%) had a history of high blood pressure, while the number from shift work group was significantly higher, with 23 individuals $(12.6 \%)$ ( $\mathrm{p}=$ 0.049 ). One individual from the daytime work group (1.4\%) and 2 from the shift work group (1.1\%) had diabetes. None of the daytime workers had dyslipidemia, while 1 of the shift workers $(0.5 \%)$ did (Table 1$)$.

Among the businesses where the research subjects worked, 8 had under 50 employees, and 9 had between 50 and 99 employees, while 2 of the businesses had 100 employees or more, and shift work was organized in 2 or 3 shifts. Among the daytime work group, 20 people (28.2\%) did office work, 16 people $(22.5 \%)$ worked in research, $14(19.7 \%)$ in administration, and $6(8.5 \%)$ in sales. All of the subjects from the shift work group worked in manufacturing: 74 people $(40.4 \%)$ worked in inspection, 36 people (19.7\%) worked in processing and pre-processing, 25 (13.7\%) as cutting, and 13 (7.1\%) as winders.

2. Physical measurements and examination findings of the research subjects

The average and standard deviation of the waist circumference for the daytime work group and the shift work group was $71.5 \pm 6.0 \mathrm{~cm}$ and $75.0 \pm 5.5 \mathrm{~cm}$, respectively, showing no significant difference. For body mass index, however the shift work group had a higher BMI at $23.9 \pm$ $2.9 \mathrm{~kg} / \mathrm{m}$ [2] versus the $22.4 \pm 3.7 \mathrm{~kg} / \mathrm{m}$ [2] for the daytime 
Table 1 General characteristics of the subjects (No(\%))

\begin{tabular}{|c|c|c|c|c|c|c|}
\hline \multicolumn{2}{|l|}{ Characteristics } & \multicolumn{2}{|c|}{ Daytime workers $(n=71)$} & \multicolumn{2}{|c|}{ Shift workers $(n=183)$} & \multirow{2}{*}{$\frac{\text { p-value }}{<0.001}$} \\
\hline Age (years) & $18-39$ & 46 & $(64.8)$ & 22 & $(12.0)$ & \\
\hline & $40-49$ & 17 & $(23.9)$ & 102 & $(55.7)$ & \\
\hline & $\geq 50$ & 8 & $(11.3)$ & 59 & $(32.2)$ & \\
\hline & Mean \pm SD & & & & & $<0.001^{\ddagger}$ \\
\hline \multirow[t]{2}{*}{ Smoking } & Yes & 1 & $(1.4)$ & 2 & $(1.1)$ & $1.000^{\dagger}$ \\
\hline & No & 70 & $(98.6)$ & 181 & $(98.9)$ & \\
\hline \multirow[t]{2}{*}{ Alcohol drinking } & Yes & 36 & $(50.7)$ & 67 & $(36.6)$ & $0.040^{*}$ \\
\hline & No & 35 & $(49.3)$ & 116 & $(63.4)$ & \\
\hline \multirow[t]{2}{*}{ Exercise } & Yes & 61 & $(85.9)$ & 129 & $(70.5)$ & $0.011^{*}$ \\
\hline & No & 10 & $(14.1)$ & 54 & $(29.5)$ & \\
\hline \multirow[t]{2}{*}{ Hypertension } & Yes & 3 & $(4.2)$ & 23 & $(12.6)$ & $0.049^{\dagger}$ \\
\hline & No & 68 & $(95.8)$ & 160 & $(87.4)$ & \\
\hline \multirow[t]{2}{*}{ DM } & Yes & 1 & $(1.4)$ & 2 & $(1.1)$ & $1.000^{+}$ \\
\hline & No & 70 & (98.6) & 181 & $(98.9)$ & \\
\hline \multirow[t]{2}{*}{ Dyslipidemia } & Yes & 0 & $(0.0)$ & 1 & $(0.5)$ & $1.000^{+}$ \\
\hline & No & 71 & (100.0) & 182 & (99.5) & \\
\hline
\end{tabular}

${ }^{*}$ calculated by chi-squared test, $\uparrow$ calculated by Fisher's exact test, $\neq$ calculated by t-test. SD, standard deviation; DM, diabetes mellitus.

worker group $(\mathrm{p}=0.043)$. The systolic blood pressure of each group was $117.3 \pm 13.0 \mathrm{mmHg}$ and $125.1 \pm$ $17.1 \mathrm{mmHg}$, the shift work group having a significantly higher rate $(\mathrm{p}=0.008)$. The diastolic blood pressure was $74.7 \pm 7.5 \mathrm{mmHg}$ and $77.5 \pm 9.3 \mathrm{mmHg}$, showing no difference between the two groups. Fasting blood glucose levels were $85.5 \pm 12.7 \mathrm{mg} / \mathrm{dL}$ and $98.4 \pm$ $37.0 \mathrm{mg} / \mathrm{dL}$, with the shift work group having significantly higher levels $(\mathrm{p}=0.003)$. The total cholesterol for the daytime work group and the shift work group was $180.6 \pm 30.8 \mathrm{mg} / \mathrm{dL}$ and $193.0 \pm 35.2 \mathrm{mg} / \mathrm{dL}$, lowdensity lipoprotein cholesterol was $103.2 \pm 26.6 \mathrm{mg} / \mathrm{dL}$ and $112.2 \pm 31.6 \mathrm{mg} / \mathrm{dL}$, and high-density lipoprotein cholesterol was $60.9 \pm 15.7 \mathrm{mg} / \mathrm{dL}$ and $59.1 \pm 15.1 \mathrm{mg} / \mathrm{dL}$, respectively, with no significant difference between the two groups. Triglyceride levels, however, were $87.8 \pm$ $58.4 \mathrm{mg} / \mathrm{dL}$ and $105.5 \pm 66.2 \mathrm{mg} / \mathrm{dL}$, respectively, revealing significantly higher levels among shift workers $(p=0.025)$ (Table 2).

3. Frequency of abnormalities in the metabolic syndrome components

Among each of the components of the diagnostic criteria, there was no significant difference between the 2 groups' waist circumference, triglyceride levels,

Table 2 Results of the physical examination and laboratory tests of the subjects

\begin{tabular}{|c|c|c|c|}
\hline $\begin{array}{l}\text { Physical examinations } \\
\text { and laboratory tests }\end{array}$ & $\begin{array}{l}\text { Daytime workers }(n=71) \\
\text { mean } \pm \text { SD }\end{array}$ & $\begin{array}{c}\text { Shift workers }(n=183) \\
\text { mean } \pm \text { SD }\end{array}$ & $p$-value ${ }^{\dagger}$ \\
\hline WC (cm) & $71.5 \pm 6.0$ & $75.0 \pm 5.5$ & 0.471 \\
\hline BMI (kg/m [2]) & $22.4 \pm 3.7$ & $23.9 \pm 2.9$ & 0.043 \\
\hline SBP $(\mathrm{mmHg})$ & $117.3 \pm 13.0$ & $125.1 \pm 17.1$ & 0.008 \\
\hline $\mathrm{DBP}(\mathrm{mmHg})$ & $74.7 \pm 7.5$ & $77.5 \pm 9.3$ & 0.139 \\
\hline $\mathrm{FBS}(\mathrm{mg} / \mathrm{dL})$ & $85.5 \pm 12.7$ & $98.4 \pm 37.0$ & 0.003 \\
\hline Total cholesterol (mg/dL) & $180.6 \pm 30.8$ & $193.0 \pm 35.2$ & 0.225 \\
\hline LDL cholesterol (mg/dL) & $103.2 \pm 26.6$ & $112.2 \pm 31.6$ & 0.117 \\
\hline TG (mg/dL) & $87.8 \pm 58.4$ & $105.5 \pm 66.2$ & 0.025 \\
\hline HDL cholesterol (mg/dL) & $60.9 \pm 15.7$ & $59.1 \pm 15.1$ & 0.540 \\
\hline
\end{tabular}

WC, waist circumference; BMI, body mass index; SBP, systolic blood pressure; DBP, diastolic blood pressure; FBS, fasting blood sugar; LDL, low density lipoprotein; $\mathrm{TG}$, triglyceride; $\mathrm{HDL}$, high density lipoprotein.

† calculated by t-test. 
and high-density lipoprotein cholesterol, whereas in the case of systolic and diastolic blood pressure and fasting blood glucose, there was a significantly higher percentage of abnormal levels within the shift work group $(\mathrm{p}<0.001)$. The prevalence of the metabolic syndrome among the daytime work group was $2.8 \%$, while the shift work group had a significantly higher prevalence of $15.3 \%$ $(\mathrm{p}=0.006)($ Table 3$)$.

\section{Logistic regression analysis results according to general characteristics and shift work}

In the univariate analysis, the greater the age, the greater the alcohol consumption, the less a worker exercised, the greater the likelihood of a worker having the metabolic syndrome. Those who did shift work were also more likely to have the metabolic syndrome $(\mathrm{p}<0.05)$. Therefore, we used age, alcohol consumption, exercise habits, and whether or not subjects did shift work, factors which had yielded p-values of 0.25 or lower in univariate analysis, as variables in a logistic regression analysis and calculated the odds ratio and its 95\% confidence interval (CI) for the metabolic syndrome. In the logistic regression analysis results, in comparison with the daytime work group, the shift work group had an odds ratio of 6.30 (95\% CI 1.24-32.15), while the other variables were not significant (Table 4).

\section{Discussion}

The clinical importance of the metabolic syndrome has been revealed through many prospective studies. Ford et al. [25] analyzed prospective studies published from 1998 to 2004 and reported that the estimated relative risk of cardiovascular disease for the metabolic syndrome, as defined by NCEP-ATP III, was 1.65 (95\% CI 1.38-1.99), and the estimated relative risk for diabetes was 2.99 (95\% CI 1.96-4.57). This showed that the metabolic syndrome was an important risk factor for developing cardiovascular disease and diabetes. Lakka et al. [26] reported their results from monitoring middle-aged men
Table 4 Logistic regression analysis for the metabolic syndrome of female workers by general characteristics and shift work $(\mathrm{N}=\mathbf{2 5 4})$

\begin{tabular}{|c|c|c|c|}
\hline Variables & & OR & $95 \% \mathrm{Cl}^{*}$ \\
\hline \multirow[t]{3}{*}{ Age } & $\leq 39$ & 1.00 & \\
\hline & $40-49$ & 0.38 & $0.10-1.46$ \\
\hline & $\geq 50$ & 1.16 & $0.30-4.57$ \\
\hline \multirow[t]{2}{*}{ Alcohol drinking } & No & 1.00 & \\
\hline & Yes & 0.59 & $0.20-1.68$ \\
\hline \multirow[t]{2}{*}{ Exercise } & No & 1.00 & \\
\hline & Yes & 0.47 & $0.21-1.07$ \\
\hline \multirow[t]{2}{*}{ Shift work } & No & 1.00 & \\
\hline & Yes & 6.30 & $1.24-32.15$ \\
\hline
\end{tabular}

$O R$, odds ratio.

${ }^{*} 95 \%$ confidence interval.

with the metabolic syndrome for 11.4 years, finding that the relative risk of coronary artery disease was 2.9 (95\% CI 1.2-7.2), while the relative risk of mortality from coronary artery disease, cardiovascular disease, and other causes was 3.6 (95\% CI 1.7-7.9), 3.2 (95\% CI 1.7-5.8), and 2.3 (95\% CI 1.5-3.4), respectively. Boden-Albala et al. [27] conducted a follow-up study on 3,298 people for an average of 6.4 years, looking at the association of the metabolic syndrome and cerebrovascular disease. They reported an association of the metabolic syndrome with the risk of cerebral infarction, the odds in men being 1.1 (95\% CI 0.6-1.9), while women had greater odds of 2.0 (95\% CI 1.3-3.1). Thus, the prevention and treatment of the metabolic syndrome before the development of cardiovascular disease and diabetes is very important. Also, the metabolic syndrome increases the risk of left ventricular hypertrophy unrelated to high blood pressure, it is associated with subclinical cardiovascular disease, arteriopathy, renal disease, and atrial fibrillation [28], and it is also associated with health problems such as fatty liver disease, polycystic ovary syndrome, cholesterol gallstone, asthma, sleep disorder, and malignant tumors [29].

Table 3 Prevalence of each criterion for the metabolic syndrome of the subjects

\begin{tabular}{|c|c|c|c|c|c|}
\hline \multirow[t]{2}{*}{ Criterion } & \multirow{2}{*}{\multicolumn{2}{|c|}{$\begin{array}{c}\text { Daytime workers }(\mathrm{n}=71) \\
\text { Number }(\%)\end{array}$}} & \multirow{2}{*}{\multicolumn{2}{|c|}{$\begin{array}{c}\text { Shift workers }(n=183) \\
\text { Number }(\%)\end{array}$}} & \multirow{3}{*}{$\begin{array}{c}\text { p-value } \\
0.674^{*}\end{array}$} \\
\hline & & & & & \\
\hline WC ( $\geq 85 \mathrm{~cm})$ & 4 & (5.6) & 13 & $(7.1)$ & \\
\hline BP $(\geq 130 / 85 \mathrm{mmHg})$ or being treated & 20 & $(28.2)$ & 92 & (50.3) & $0.001^{\dagger}$ \\
\hline FBS $(\geq 100 \mathrm{mg} / \mathrm{dL}$ ) or being treated & 3 & $(4.2)$ & 45 & (24.6) & $<0.001^{\dagger}$ \\
\hline $\mathrm{TG}(\geq 150 \mathrm{mg} / \mathrm{dL})$ or being treated & 7 & $(9.9)$ & 36 & (19.7) & $0.061^{\dagger}$ \\
\hline $\mathrm{HDL}(<50 \mathrm{mg} / \mathrm{dL})$ or being treated & 18 & $(25.4)$ & 49 & (26.8) & $0.817^{\dagger}$ \\
\hline Metabolic syndrome $e^{\ddagger}$ & 2 & $(2.8)$ & 28 & $(15.3)$ & $0.006^{\dagger}$ \\
\hline
\end{tabular}

WC, waist circumference; FBS, fasting blood sugar; TG, triglyceride; HDL, high density lipoprotein.

*calculated by Fisher's exact test, + calculated by $\times{ }^{2}$ test.

₹ Metabolic syndrome is any 3 of these 5 criteria: WC $\geq 85 \mathrm{~cm}, \mathrm{BP} \geq 130 / 85 \mathrm{mmHg}, \mathrm{FBS} \geq 100 \mathrm{mg} / \mathrm{dL}, \mathrm{TG} \geq 150 \mathrm{mg} / \mathrm{dL}$ and HDL $<50 \mathrm{mg} / \mathrm{dL}$ or being medicated for the same conditions. 
The prevalence rate of the metabolic syndrome in South Korean adults increases with age [30]. In this study, we looked at the prevalence of the metabolic syndrome as well as abnormal values of each component criterion for different age groups. For the age brackets of under 40, 40-49 years old, and 50 and above, blood pressure was $26.5 \%, 44.5 \%$, and $61.2 \%$, respectively; fasting blood glucose was $7.4 \%, 16.0 \%$, and $35.8 \%$; waist circumference was $7.4 \%, 5.0 \%$, and $9.0 \%$; triglyceride levels were $10.3 \%, 13.4 \%$, and $29.9 \%$; low high-density lipoprotein cholesterolemia was $22.1 \%, 21.0 \%$, and $40.3 \%$; and the prevalence of the metabolic syndrome was $7.4 \%, 7.6 \%$, and $23.9 \%$, respectively. These results showed signs of an increase in the prevalence of the metabolic syndrome and abnormalities of each metabolic syndrome component as the age brackets increased. These results were similar to those of a study on the factors related to the metabolic syndrome in dockyard and electronics manufacturing workers [21,23]. The subjects in our study aged 30 or over comprised 223 individuals $(87.8 \%)$, of which $13.5 \%$ had the metabolic syndrome. This was lower than the $25.6 \%$ metabolic syndrome prevalence in women aged 30 and over reported in the Korean National Health and Nutrition Examination Surveys of 2007-2010. One reason for this discrepancy might be found in the KNHANES, which reported that odds ratio of the metabolic syndrome for full-time homemakers was 1.85 times greater than for nonhomemakers. According to research by Waggoner et al. [31], the lower prevalence of the metabolic syndrome for women with jobs can be attributed to the healthy worker effect.

Smoking is an example of another factor related to the development of the metabolic syndrome. Smoking, a risk factor in coronary artery disease, increases total cholesterol and triglyceride levels, induces insulin resistance, hyperinsulinemia, and low high-density lipoprotein cholesterol, and appears to raise the risk of the metabolic syndrome [32]. In addition, smoking shows a strong correlation with the five diagnostic criteria for the metabolic syndrome proposed by ATP III. David et al. [33] reported that smoking itself is associated with a high-fat and low-fiber diet, which increases total cholesterol and triglyceride levels. As only three out of the 254 subjects in this study were smokers, the small number of subjects made the confirmation of an association between smoking and the metabolic syndrome difficult.

Through a number of studies, it has become clear that a moderate amount of alcohol consumption lowers the risk of heart disease. A moderate amount of alcohol consumption inhibits blood coagulation and platelet aggregation and also increases high-density lipoprotein cholesterol, by which it is believed to have cardioprotective effects. On the other hand, the overconsumption of alcohol is known to increase triglyceride levels and raise blood pressure [34]. Meanwhile, there are reports that, compared with men, women are more susceptible to health hazards from alcohol consumption [35]. In the United States Recommended Dietary Allowance proposed in 2005, the recommended alcohol consumption is no more than two glasses per day for men, and half of that amount for women, no more than 1 glass a day [36]. In this study as well, while the prevalence of the metabolic syndrome was higher in those who drank alcohol than in those who did not, it was not statistically significant.

Exercise is known to reduce overall metabolic risk factors, improving lipid metabolism and lowering blood pressure in patients with high blood pressure, reducing insulin resistance, and improving hyperglycemia [37,38]. In this study, while those who exercised regularly at least once a week for $30 \mathrm{~min}$ or more tended to have lower triglyceride and fasting blood glucose levels, higher levels of high-density lipoprotein cholesterol, and a lower prevalence of the metabolic syndrome compared with those who did not exercise, the differences were not statistically significant.

In this study, shift work was confirmed to be a risk factor for the metabolic syndrome in female workers. This relationship was also found in a study by Li et al. [39], which found that the odds ratio for the metabolic syndrome in both male and female shift workers was 1.87 (95\% CI 1.13-3.08), and in the three-year follow-up study by Kawada et al. [40], the odds ratio for male double-shift workers was 1.43 (95\% CI 1.05-1.95). However, a study by Puttonen et al. [41] found the odds ratio of the metabolic syndrome in men to be 1.83 (95\% CI 1.13-2.96), with no meaningful difference from the prevalence in women. These findings differ from the results of our study. That shift work has a direct association with the development of cardiovascular disease can be inferred from the following studies: Research by Esquirol et al. [42,43] found through a meta-analysis of 17 studies on shift work-related health hazards that shift workers, both male and female, had 1.4 times greater odds of developing cardiovascular disease than did daytime workers. Vyas et al. [44], through a systematic review and meta-analysis of 34 experiments conducted at Canada's Western University comprising $2,011,935$ subjects, found the odds ratios for myocardial infarction, cerebral infarction, and coronary artery disease in shift workers compared to daytime workers were 1.23 (95\% CI 1.15-1.32), 1.05 (95\% CI 1.01-1.09), and 1.24 (95\% CI 1.10-1.39), respectively.

Factors such as stress, lack of sleep, and changes in health behavior are involved in the mechanism of the metabolic syndrome [45]. The association of the metabolic syndrome and stress has been confirmed by many studies $[46,47]$. When stress is continuously 
undergone, an increase in adrenocortical hormones caused by hypothalamus-pituitary-adrenal axis dysregulation leads to metabolic dysfunctions such as high blood pressure, hardening of the arteries, insulin resistance, and dyslipidemia. It also produces an anti-insulin effect, causing a rise in blood glucose levels, and can cause visceral obesity by accumulating abdominal fat $[48,49]$. In addition, studies have found that partial sleep restriction causes a change in the hormones that regulate the ingestion of food, ghrelin (increases after sleep restriction) and leptin (decreases after sleep restriction), which increases appetite [50], while a lack of sleep reduces glucose tolerance and insulin-sensitivity, and increases blood pressure [45]. According to research by Lee et al. [51], the stress received by shift workers is significantly high compared with that of daytime workers, the same of which is true for sleep disorders [52]. Ordinarily in humans, during the day, glycometabolism is accelerated and fat storage occurs. While sleeping at night, glucoseuse lowers and lipometabolism occurs. Therefore, having to ingest food at night due to shift work, when insulinsensitivity is at its lowest, can lead to metabolic dysfunction [45].

For reasons such as these, stress management and the management of appropriate eating habits and lifestyle habits by shift workers appears necessary in order to reduce the prevalence of the metabolic syndrome. Likewise, employers must work to prevent illness by taking actions such as giving shift workers sufficient rest time, checking the state of their health on a frequent basis, managing the working environment, and providing antismoking/drinking education, daily physical activities, and healthy meals. On a national level, there appears to be a need for oversight to ensure compliance with working hour requirements, night work restrictions, and vacation provision, as well as the establishment of policies to reduce the number of night-shift workers.

Among the limitations of this study were the difficulty in determining causal relationships as a cross-sectional study, and the exclusion of the investigation of the influence of socioeconomic factors on the metabolic syndrome. For example, at the time of selecting the research subjects, in order to minimize employmentrelated biases, we selected subjects who were working in the fabric industry. However, when we divided the subjects by office work and manufacturing work, the manufacturing jobs were mainly categorized as shift work, and office work became mostly day work. Because of this, the effect of shift work became conflated with the type of work, and our being unable to separate this was a limitation. An additional drawback was that we could not take the qualitative aspects of each variable, such as the shift work hours or the intensity of the work, into consideration.

\section{Conclusion}

Our confirmation that shift labor can influence the prevalence of the metabolic syndrome in female workers doing such work is of value. What is needed from this point on are large-scale prospective studies on the management and prevention of the metabolic syndrome that involve more female worker subjects and that take into account socioeconomic factors as well as the other factors investigated in our study.

\section{Competing interests}

The authors declare that they have no competing interests.

\section{Authors' contributions}

HHY: Study concept and design, Drafting of the manuscript. JUJ: Analysis of data. JS: Technical support. JMJ: Critical revision of the manuscript. All authors read and approve the final manuscript.

Received: 29 August 2013 Accepted: 8 October 2013

Published: 1 November 2013

\section{References}

1. Eckel RH, Grundy SM, Zimmet PZ: The metabolic syndome. Lancet 2005, 365:1415-1428.

2. Reaven GM: Banting lecture 1988. Role of insulin resistance in human disease. Diabetes 1988, 37(12):1595-1607.

3. Alberti KG, Zimmet PZ: Definition, diagnosis and classification of diabetes mellitus and its complications. Part 1: diagnosis and classification of diabetes mellitus provisional report of a WHO consultation. Diabet Med 1998, 15(7):539-553.

4. Expert Panel on Detection, Evaluation, and Treatment of High Blood Cholesterol in Adults: Executive summary of the third report of the National Cholesterol Education Program (NCEP) expert panel on detection, evaluation, and treatment of high blood cholesterol in adults (adult treatment panel III). JAMA 2001, 285(19):2486-2497.

5. Alberti KG, Zimmet $P$, Shaw J: The metabolic syndrome-a new worldwide definition. Lancet 2005, 366(9491):1059-1062.

6. Grundy SM, Cleeman JI, Daniels SR, Donato KA, Eckel RH, Franklin BA, Gordon DJ, et al: Diagnosis and management of the metabolic syndrome: an American Heart Association/National Heart, Lung, and Blood Institute Scientific Statement. Circulation 2005, 112(17):2735-2752.

7. Isomaa B, Almgren P, Tuomi T, Forsen B, Lahti K, Nissen M, Taskinen MR, et al: Cardiovascular morbidity and mortality associated with the metabolic syndrome. Diabetes Care 2001, 24(4):683-689.

8. Ford ES, Giles WH, Mokdad AH: Increasing prevalence of the metabolic syndrome among U.S. Adults. Diabetes Care 2004, 27(10):2444-2449.

9. Namdo news: Metabolic syndrome prevalence $28.8 \%$ of 30-year old and over (translated by Ye HH); 2013. http://www.ndnews.co.kr/sub_read.html? uid=8424 [cited 15 May 2013].

10. Trivedi T, Liu J, Probst JC, Martin AB: The metabolic syndrome: are rural residents at increased risk? J Rural Health 2013, 29(2):188-197.

11. Yoo $\mathrm{KH}$ : Sleeping patterns and gastrointestinal disorders according to the shift workers in female textile workers. Korean J of preventive medicine 1994, 27(1):74-83. (Korean) -.

12. Szosland D: Shift work and metabolic syndrome, diabetes mellitus and ischaemic heart disease. Int J Occup Med Environ Health 2010, 23(3):287-291.

13. Park TJ, Paek DM, Joh KO, Park JS, Cho SI: The relationship between shift work and work-related injuries among Korean workers. Korean J Occup Environ Med 2012, 24(1):52-60. (Korean) -.

14. Klerman EB: Clinical aspects of human circadian rhythms. J Biol Rhythms 2005, 20:375-386.

15. Yoon JS, Guk SH, Lee HY, Shin IS, Kim AJ: Sleep pattern, job satisfaction and quality of life in nurses on rotating shift and daytime fixed work schedules. Journal of Korean neuropsychiatric assocation 1999, 38(4):713-721. (Korean).

16. Harrington JM: Shift work and health-a critical review of the literature on working hours. Ann Acad Med Singapore 1994, 23(5):699-705.

17. Ha MN, Kim JY, Park JS, Chung HK: Influence of shiftwork duration on blood pressure and heart and heart rate variability in short rotating 8-hour shiftworkers. Korean J Occup Environ Med 2001, 13(2):180-189. (Korean). 
18. Sookoian S, Gemma C, Fernández Gianotti T, Burgueño A, Alvarez A, González CD, Pirola CJ: Effects of rotating shift work on biomarkers of metabolic syndrome and inflammation. J Intern Med 2007, 261(3):285-292.

19. Knutsson A, Alfredsson L, Karlsson B, Akerstedt T, Fransson El, Westerholm P, Westerlund $\mathrm{H}$ : Breast cancer among shift workers: results of the WOLF longitudinal cohort study. Scand J Work Environ Health 2013, 39(2):170-177.

20. Moon JH, Lee SJ, Park JD: The risk factors of metabolic syndrome and its relation with r-GTP in steel-mill workers. Korean J Occup Environ Med 2007, 19(1):17-25. (Korean).

21. Kim YH, Park RJ, Park WJ, Kim MB, Moon JD: Predictors of metabolic syndrome among shipyard workers and its prevalence. Korean J Occup Environ Med 2009, 21(3):209-217. Korean.

22. Ha MN, Roh SC, Park JS: Shiftwork duration and metabolic risk factors of cardiovascular disease. Korean J Occup Environ Med 2003, 15(2):132-139. Korean.

23. Choi ES: The metabolic syndrome and associated risk factors among male workers in an electronics manufacturing company. Korean J Occup Environ Med 2006, 18(1):35-45.

24. Lee SY, Park HS, Kim SM, Kwon HS, Kim DY, Kim DJ, Cho GJ, et al: Cut-off points of waist circumference for defining abdominal obesity in the Korean population. Korean J Obes 2006, 15:1-9. Korean.

25. Ford ES: Risks for all-cause mortality, cardiovascular disease, and diabetes associated with the metabolic syndrome. Diabetes Care 2005, 28:1769-1778.

26. Lakka HM, Laaksonen DE, Lakka TA, Niskanen LK, Kumpusalo E, Tuomilehto J, Salonen JT: The metabolic syndrome and total and cardiovascular disease mortality in middle-aged men. JAMA 2002, 288(21):2709-2716.

27. Boden-Albala B, Sacco RL, Lee HS, Grahame-Clarke C, Rundek T, Elkind MV, Wright C, et al: Metabolic syndrome and ischemic stroke risk: Northern Manhattan study. Stroke 2008, 39(1):30-35.

28. Guize L, Pannier B, Thomas F, Bean K, Jégo B, Benetos A: Recent advances in metabolic syndrome and cardiovascular disease. Arch Cardiovasc Dis 2008, 101(9):577-583.

29. Grundy SM, Brewer HB, Cleeman Jl, Smith SC, Lenfant C: Definition of metabolic syndrome: Report of the National Heart, Lung, and Blood Institute/American Heart Association conference on scientific issues related to definition. Circulation 2004, 109:433-438.

30. Korean centers for disease control and prevention: The 3rd in-depth study of Korean national health and nutrition examination survey (translated by Ye HH). Korean: health screening sector; 2007:4.

31. Waggoner JK, Kullman GJ, Henneberger PK, Umbach DM, Blair A, Alavanja MC, Kamel F, et al: Mortality in the agricultural health study, 1993-2007. Am J Epidemiol 2011, 173(1):71-83.

32. Facchini FS, Hollenbeck CB, Jeppesen J, Chen YD, Reaven GM: Insulin resistance and cigarette smoking. Lancet 1992, 339:1128-1130.

33. Cundiff DK: Diet and tobacco use: analysis of data from the diabetic control and complications trial, a randomized study. MedGenMed 2002, 4:2

34. Corrao G, Rubbiati L, Bagnardi V, Zambon A, Poikolainen K: Alcohol and coronary heart disease: a meta-analysis. Addiction 2000, 95:1505-1523.

35. Choi EY, Im YS, Kim KN, Park CY, Kim HJ, Cho BL, et al: Alcohol habits in Korea. J Korean Acad Fam Med 1998, 19:858-869. Korean.

36. US Department of Agriculture: E report of the dietary guidelines advisory committee on dietary guidelines for Americans, 2005. Washington: US Department of Agriculture; 2005.

37. Jennings G, Nelson L, Nestel P, Esler M, Korner P, Burton D, et al: The effects of changes in physical activity on major cardiovascular risk factors, hemodynamics, sympathetic function, and glucose utilization in man: a controlled study of four levels of activity. Circulation 1986, 73(1):30-40.

38. Pan XR, Li GW, Hu YH, Wang JX, Yang WY, An ZX, et al: Effects of diet and exercise in preventing NIDDM in people with impaired glucose tolerance. The Da Qing IGT and Diabetes Study. Diabetes Care 1997, 20(4):537-544.

39. Li Y, Sato Y, Yamaguchi N: Shift work and the risk of metabolic syndrome: a nested case-control study. Int J Occup Environ Health 2011, 17(2):154-160.

40. Kawada T, Otsuka T: Effect of shift work on the development of metabolic syndrome after 3 years in Japanese male workers. Arch Environ Occup Health 2014, 69(1):55-61.

41. Puttonen S, Viitasalo K, Harma M: The relationship between current and former shift work and the metabolic syndrome. Scand J Work Environ Health 2012, 38(4):343-348.

42. Esquirol Y, Bongard V, Mabile L, Jonnier B, Soulat JM, Perret B: Shift work and metabolic syndrome: respective impacts of job strain, physical activity, and dietary rhythms. Chronobiol Int 2009, 26(3):544-559.
43. Esquirol Y, Perret B, Ruidavets JB, Marquie JC, Dienne E, Niezborala M, Ferrieres J: Shift work and cardiovascular risk factors: new knowledge from the past decade. Arch Cardiovasc Dis 2011, 104(12):636-668.

44. Vyas MV, Garg AX, lansavichus AV, Costella J, Donner A, Laugsand LE, Janszky I, Mrkobrada M, Parraga G, Hackam DG: Shift work and vascular events: systematic review and meta-analysis. BMJ 2012, 345:e4800.

45. Tucker P, Marquié JC, Folkard S, Ansiau D, Esquirol Y: Shiftwork and metabolic dysfunction. Chronobiol Int 2012, 29(5):549-555.

46. Bara AC, Arber S: Working shifts and mental health-findings from the British household panel survey (1995-2005). Scand J Work Environ Health 2009, 35(5):361-367.

47. Driesen K, Jansen NW, Kant I, Mohren DC, van Amelsvoort LG: Depressed mood in the working population: associations with work schedules and working hours. Chronobiol Int 2010, 27(5):1062-1079.

48. Vanitallie TB: Stress: a risk factor for serious illness. Metabolism 2002, $51: 40-45$.

49. Jung JW, Shin HC, Park YW, Kim CH, Cheong SY, Sung EJ: The relationship between metabolic syndrome, stress and depression. Korean J Health Promot Dis Prev 2004, 4(1):10-17. Korean.

50. Spiegel K, Tasali E, Penev P, Van Cauter E: Brief communication: Sleep curtailment in healthy young men is associated with decreased leptin levels, elevated ghrelin levels, and increased hunger and appetite. Ann Intern Med 2004, 141(11):846-850.

51. Lee KJ, Kim JJ, Lee NS: Impact of shift work and work stress on job satisfaction in manufacture working women. Journal of Soonchunhyang Medical Science 2009, 15(1):89-98. Korean.

52. Lee JT, Lee KJ, Park JB, Lee KW, Jang KY: The relations between shiftwork and sleep disturbance in a university hospital nurses. Korean J Occup Environ Med 2007, 19(3):223-230. Korean.

doi:10.1186/2052-4374-25-33

Cite this article as: Ye et al:: The Association between Shift Work and the Metabolic Syndrome in Female Workers. Annals of Occupational and Environmental Medicine 2013 25:33.

\section{Submit your next manuscript to BioMed Central and take full advantage of:}

- Convenient online submission

- Thorough peer review

- No space constraints or color figure charges

- Immediate publication on acceptance

- Inclusion in PubMed, CAS, Scopus and Google Scholar

- Research which is freely available for redistribution 